\title{
TAVI Care and Cure, the Rotterdam multidisciplinary program for patients undergoing transcatheter aortic valve implantation: Design and rationale
}

\author{
Marjo J.A.G. De Ronde-Tillmans a, Jeannette A. Goudzwaard ${ }^{\mathrm{b}}$, Nahid El Faquir ${ }^{\text {a }}$, Nicolas M. van Mieghem ${ }^{\text {a }}$, \\ Francesco U.S. Mattace-Raso ${ }^{\mathrm{b}}$, Paul A. Cummins ${ }^{\mathrm{a}}$, Mattie J. Lenzen ${ }^{\mathrm{a}}$, Peter P.T. de Jaegere ${ }^{\mathrm{a}, *}$ \\ a Erasmus Medical Center, Department of Cardiology, Thoraxcenter, the Netherlands \\ b Erasmus Medical Center, Section of Geriatrics, Department of Internal Medicine, the Netherlands
}

\section{A R T I C L E I N F O}

\section{Article history:}

Received 21 January 2019

Received in revised form 25 July 2019

Accepted 2 December 2019

Available online 16 December 2019

\section{Keywords:}

Aortic stenosis (AS)

Health related quality of life (HrQoL)

Transcatheter aortic valve implantation (TAVI)

Patient-centered care

\begin{abstract}
A B S T R A C T
Background: The capacity of TAVI-programs and numbers of sites performing TAVI has rapidly increased. This necessitated the initiation of the Rotterdam TAVI Care \& Cure Program, aiming to improve patient-centered care during the TAVI pathway.

Methods: Consenting patients with severe aortic stenosis and an indication for TAVI will be included. The TAVI Care \& Cure program will facilitate prognostic contributions to improve outcomes, patient satisfaction and quality of life in patients with valvular heart disease who are treated with a transcatheter aortic valve implantation in collaboration with the departments of cardiology, cardio-thoracic surgery, anesthesiology and geriatrics.

Conclusion: With a single center observational registry, we aim to assess the TAVI patient clinical pathway, focusing on pre, peri and post interventional variables including functional status and HRQoL. We will evaluate the patient's complexity by applying an extended multidisciplinary approach, which includes a systematic application of geriatric assessments of frailty and cognitive function.
\end{abstract}

(c) 2019 Published by Elsevier B.V.

\section{Introduction}

Transcatheter aortic valve implantation (TAVI) is increasingly being utilized to treat patients with severe aortic stenosis (AS) who are considered at intermediate or high risk for surgical aortic valve replacement (SAVR). TAVI, a less-invasive therapeutic option, is expected to become the standard treatment in all patients with aortic stenosis but will predominantly be applied in an increasingly elderly population given the increase of this population group [1-3]. Elderly patients differ from younger patients in terms of frailty (a state of reduced physical, cognitive and social functioning, resulting in a reduction of reserve capacity for dealing with stressors) [4] due to a higher prevalence of medical co-morbidities leading to a more pronounced reduction in functional status and health related quality of life (HRQoL).

Despite improvements in immediate outcomes (i.e. safety) as a result of enhanced operator experience, progress in device technology and post-operative care, a proportion of patients do not survive beyond one year or at best show limited or no improvement in HRQoL after TAVI $[1,2,5]$. This is particularly evident for the elderly patient ( $>80$ years) necessitating a more delicate and balanced decision-making (risk/benefit

\footnotetext{
* Corresponding author at: 's Gravendijkwal 230, 3015 CE Rotterdam, the Netherlands. E-mail address: p.dejaegere@erasmusmc.nl (P.P.T. de Jaegere).
}

assessment) including the understanding of other factors that determine immediate and above all long-term outcomes [6-9]. In this context frailty is of significance, as it is associated with chronic diseases and increased age, negatively influencing morbidity and mortality after TAVI. Importantly, through advocacy of the European Society of Cardiology, frailty has now been incorporated into the decisionmaking process [10].

Also other components such as mental status, nutrition and socioeconomic status, which are not only relevant for the elderly patient population, will be taken into account. This in combination with a higher prevalence of medical antecedents and co-morbidities renders formulating treatment strategies in the elderly complex and requires further analysis into whether specific geriatric interventions before and/or after TAVI may improve immediate and long-term outcome after TAVI [10]. For this reason, a dedicated TAVI program entitled TAVI Care $\&$ Cure was initiated in our institution of which the details are herein further described.

\section{Study design}

The TAVI Care \& Cure study is a prospective single-center multidisciplinary observational cohort study in which a comprehensive set of predefined cardiovascular and non-cardiovascular variables are 
collected (Table 1a). "Care" entails the management of the pre and post interventional patient pathway whilst "Cure" entails the interventional treatment phase. Inclusion criteria are all consecutive patients with severe symptomatic AS, not considered for conventional open heart valve surgery techniques, who are deemed eligible for TAVI by a multidisciplinary heart valve team. Furthermore aspects as technical suitability, frailty and co-morbidities are considered in the decision making process. Patients will be excluded if co-morbidities and/or their general condition is not expected to improve their quality of life and/or a survival expectation of $<1$ year. Candidates who are not eligible for TAVI will be excluded from this study. Inherent in this observation cohort study, no control group will be used.

Patients older than 70 years with an indication for aortic valve replacement therapy (outpatient cardiology assessment) are referred for comprehensive geriatric assessment (CGA) which consists of hetero, social and functional anamnesis, medication review and frailty assessment to determine deficits in geriatric domains by using validated frailty assessment tools [11].

The primary objective of the TAVI Care \& Cure program is to improve the treatment and care of patients with aortic stenosis undergoing a TAVI following a novel, dedicated clinical TAVI-pathway. This pathway encompasses pre-admission assessments, diagnostic work-ups, heart team consultations, interventional treatment and lastly outpatient follow-up. Collected data will provide additional information concerning the understanding of the safety and device performance and also how to treat patients in a real world setting including HRQoL.

Secondary objectives are to access the role of frailty in this population and to quantify patient characteristics and criteria for possible early discharge eligibility.

For these purposes immediate outcomes and clinical endpoints (i.e. safety, life-threatening or major bleeding, major vascular complications, in-hospital major stroke, in-hospital acute kidney injury, and 30-day mortality) are assessed using the Valve Academic Research Consortium criteria (VARC-2 criteria) [12] in addition to the occurrence of non-cardiovascular events with emphasis on delirium at time points summarized in Table 1a.
Efficacy of treatment is assessed by monitoring survival freedom from major adverse cerebro-cardiovascular events, functional class and HrQoL at 30 days, one, three, and five year. Assessment of utility or futility of treatment will be based upon analysis of long-term outcomes such as survival, survival free from stroke, reduction or loss in/ of ADL. These analyses will help to formulate improvements in treatment allocation, patient preparation and postoperative care.

The Medical Ethics Committee of the Erasmus Medical Center reviewed the study (MEC-2014-277) and since this study was not subjected to the Dutch Medical Research Involving Human Subjects Act no approval was required. The study will be performed according to the Helsinki Declaration and all patients must consent for participation.

\section{The TAVI pathway}

\subsection{Diagnostic assessments}

Cardiac and geriatric examinations and assessments will be performed and include medical history and physical assessments, 12-lead ECG, laboratory results, thorax X-rays, diagnostic coronary angiogram, multi-slice computed tomography (MSCT), trans-thoracic and/or trans esophageal echocardiography and quality of life measurements. The following geriatric domains will be assessed: cognition and nutritional status, (instrumental) activity of daily living, mobility and muscle loss (see Table $1 \mathrm{~b}$ for used instruments) [13-18].

\subsection{Patient selection - multidisciplinary heart valve team meeting}

The TAVI Care \& Cure program has been developed and initiated with the collaboration of the departments of cardiology, cardiothoracic surgery, anesthesiology and geriatrics.

Using a well-designed multidisciplinary approach with collaborative input of diverse specialists of the heart valve team, the treatment decision process is not only thoroughly discussed leading to an improved treatment performance but also essential consideration is given to the

Table 1a

Cardiology assessments.

\begin{tabular}{|c|c|c|c|c|c|c|c|c|c|c|}
\hline Time-points & $\begin{array}{l}\text { Pre } \\
\text { admission } \\
\text { assessment }\end{array}$ & $\begin{array}{l}\text { Day of } \\
\text { admission }\end{array}$ & Peri-procedural & $\begin{array}{l}2-4 \mathrm{~h} \\
\text { ICCU } \\
\text { ward }\end{array}$ & $\begin{array}{l}\text { Post-procedural: } \\
\text { days } 1-5\end{array}$ & Discharge & $\begin{array}{l}4 \text { weeks } \\
\text { FU }\end{array}$ & $\begin{array}{l}12 \text { months } \\
\text { FU }\end{array}$ & $\begin{array}{l}3 \text { years } \\
\text { FU }\end{array}$ & $\begin{array}{l}5 \text { years } \\
\text { FU }\end{array}$ \\
\hline Blood* $^{*}$ & $\mathrm{X}$ & $\mathrm{X}$ & & & $\mathrm{X}$ & $\mathrm{X}$ & $\mathrm{X}$ & $\mathrm{X}$ & $\mathrm{X}$ & $\mathrm{X}$ \\
\hline 12-Lead ECG & $\mathrm{X}$ & $\mathrm{X}$ & & $\mathrm{X}$ & $\mathrm{X}$ & $\mathrm{X}$ & $\mathrm{X}$ & $\mathrm{X}$ & $\mathrm{X}$ & $\mathrm{X}$ \\
\hline NYHA \& CCS class & $\mathrm{X}$ & & & & & & $\mathrm{X}$ & $\mathrm{X}$ & $\mathrm{X}$ & $\mathrm{X}$ \\
\hline VARC-2 definitions & $\mathrm{X}$ & & & & & & $\mathrm{X}$ & $\mathrm{X}$ & $\mathrm{X}$ & $\mathrm{X}$ \\
\hline Trans thoracic echo & $\mathrm{X}$ & & $\mathrm{X}$ & $\mathrm{X}$ & & $\mathrm{X}$ & & & & \\
\hline Multi slice computer tomography & $\mathrm{X}$ & & & & & & & & & \\
\hline Coronary angiography & $\mathrm{X}$ & & & & & & & & & \\
\hline Informed consent & & $\mathrm{X}$ & & & & & & & & \\
\hline Screening on allergic for contrast medium & & $\mathrm{X}$ & & & & & & & & \\
\hline Pre-hydration prophylaxes & & $\mathrm{X}$ & & & & & & & & \\
\hline $\begin{array}{l}\text { Endocarditis prophylaxes (if indicated } \\
\text { lifelong) }\end{array}$ & & $\mathrm{X}$ & $\mathrm{X}$ & & & $\mathrm{X}$ & & & & \\
\hline Anti-thrombotic prophylaxes & & $\mathrm{X}$ & $\mathrm{X}$ & $\mathrm{X}$ & $\mathrm{X}$ & $\mathrm{X}$ & & & & \\
\hline Telemonitoring & & & & & $\mathrm{X}$ & & & & & \\
\hline Thorax X-ray & & & & $\mathrm{X}$ & & & & & & \\
\hline HR-QoL: EQ-5D \& VAS & $\mathrm{X}$ & & & & & & $\mathrm{X}$ & $\mathrm{X}$ & $\mathrm{X}$ & $\mathrm{X}$ \\
\hline Temporary pacemaker & & & If indicated & Removed & & & & & & \\
\hline Urinary catheter & & & If indicated & & & Removed & & & & \\
\hline Observation ${ }^{* *}$ & & & & $\mathrm{X}$ & $\mathrm{X}$ & & & & & \\
\hline Medication & & & & $\mathrm{X}$ & $\mathrm{X}$ & $\mathrm{X}$ & $\mathrm{X}$ & $\mathrm{X}$ & $\mathrm{X}$ & $\mathrm{X}$ \\
\hline $\begin{array}{l}\text { Mobilization/ambulation } 4-6 \text { h post } \\
\text { procedure, revalidation (If indicated } \\
\text { physiotherapy) }\end{array}$ & & & & & $\mathrm{X}$ & $\mathrm{X}$ & & & & \\
\hline If PPM/ICD implantation PM-control & & & & & & $\mathrm{X}$ & $\mathrm{X}$ & $\mathrm{X}$ & $\mathrm{X}$ & $\mathrm{X}$ \\
\hline
\end{tabular}

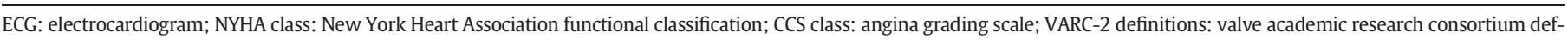

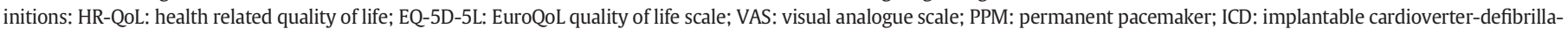
tor; e-GFR: estimated glomerular filtration rate; CRP: C-reactive protein; NT-pro BNP: pro b-type natriuretic peptide.

* Blood: e-GFR, cardiac enzymes, ureum, creatinine, CRP, NT-pro BNP, hemoglobin.

** Active clotting time (ACT), heamodynamics, arrhythmias, conduction-disturbances, bleeding, vascular complications, neurological disorders (stroke, delirium). 
Table 1b

Geriatric assessments.

\begin{tabular}{|c|c|c|c|c|c|c|c|c|c|c|}
\hline Time-points & $\begin{array}{l}\text { Pre } \\
\text { admission } \\
\text { assessment }\end{array}$ & $\begin{array}{l}\text { Day of } \\
\text { admission }\end{array}$ & Peri-procedural & $\begin{array}{l}2-4 \mathrm{~h} \\
\text { ICCU } \\
\text { ward }\end{array}$ & $\begin{array}{l}\text { Post-procedural: } \\
\text { days } 1-5\end{array}$ & Discharge & $\begin{array}{l}4 \text { weeks } \\
\text { FU }\end{array}$ & $\begin{array}{l}12 \text { months } \\
\text { FU }\end{array}$ & $\begin{array}{l}3 \text { years } \\
\text { FU }\end{array}$ & $\begin{array}{l}5 \text { years } \\
\text { FU }\end{array}$ \\
\hline Functional anamnesis* & $\mathrm{X}$ & & & & & & & $\mathrm{X}$ & & \\
\hline Social anamnesis** & $\mathrm{X}$ & & & & & & & $\mathrm{X}$ & & \\
\hline Cognitive function & $\mathrm{X}$ & & & & & & & $\mathrm{X}$ & & \\
\hline HR-QoL: RAND SF-36 & $\mathrm{X}$ & & & & & & & $\mathrm{X}$ & & \\
\hline $\begin{array}{l}\text { Mobility: time up-and go } \\
\text { test }\end{array}$ & $\mathrm{X}$ & & & & & & & & & \\
\hline 5 meter walking test & $\mathrm{X}$ & & & & & & & & & \\
\hline MMSE & $\mathrm{X}$ & & & & & & & & & \\
\hline Medication & $\mathrm{X}$ & & & & & & & & & \\
\hline Frailty assessment & $\mathrm{X}$ & & & & & & & & & \\
\hline Handgrip strength test & $\mathrm{X}$ & & & & & & & & & \\
\hline Consult geriatrician & $\mathrm{X}$ & $\mathrm{X}$ & & $\mathrm{X}$ & If indicated & & & & & \\
\hline No geriatric involvement & & & $\mathrm{X}$ & & & & $\mathrm{X}$ & & & \\
\hline Delirium-observation & $\mathrm{X}$ & $\mathrm{X}$ & & $\mathrm{X}$ & If indicated & & & & & \\
\hline
\end{tabular}

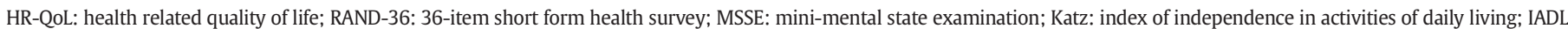

(Lawton \& Brody): the Lawton Instrumental Activities of Daily Living scale; MUST: Malnutrition Universal Screening Tool.

* Functional anamnesis: ADL (KATZ), iADL (Lawton \& Brody), independence, fallrisk, nutritional status (MUST) and incontinence.

** Social anamnesis: married, divorced, widowed, (no) children, life events, care, living environment.

potential risks and expected benefits of the selected treatment strategy. For instance, prevention of post procedural complications are deliberated in terms of either physical function such as stroke, vascular complications, renal failure, paravalvular leak and conduction disorders and in terms of cognitive function such as delirium. The treatment decision, incorporating diagnosis, complexity and multiple co-morbidities, be it for optimum medical therapy, TAVI or SAVR, are taken at the weekly multidisciplinary heart valve team meeting (Fig. 1). Importantly, the use of a multidisciplinary heart valve team for the management of patients with valvular heart diseases is strongly recommended (Class I, level C) in the current ESC guidelines [10].

All patients accepted, for either a TAVI or SAVR procedure, are scheduled for a preoperative visit at the outpatient clinic anesthesiology in order to complete the pre-procedural diagnostic workup.

\subsection{Intervention procedure}

The TAVI-procedure is performed under local anesthesia and antibiotic prophylaxis [10] in a cathlab suite with full facilities for general anesthesia, echocardiography and cardiopulmonary support if needed. Any commercially available trans catheter heart valve (THV) can be used. In our institution the balloon expandable Edwards Sapien 3 valve (Edwards Lifesciences Corp., Irvine, California), the selfexpandable Acurate neo valve (Boston Scientific, Marlborough, Massachusetts) and the self-expandable Evolute R-and Pro valve (Medtronic Inc. Minneapolis, Minnesota) are currently used. Vascular access and pre-closure is performed under echo-guidance. After vascular access, all patients receive cerebral protection using a cerebral protection filter unless the anatomy of the brachiocephalic and/or left common carotid artery precludes its use or is contra-indicated $[19,20]$. The valve size selection is based upon the screening MSCT of the aortic root and the valve implantation is performed without pre-balloon valvuloplasty (direct valve implantation). Contrast angiography and Trans Thoracic Echocardiography are used for implantation guidance and post implantation evaluation. In the case of a high degree atrioventricular (AV) block during the procedure a temporary pacemaker (TPM) is left in situ up to $24 \mathrm{~h}$ and removed when clinically justified. Hemostasis is achieved by using either a plug-or suture based vessel closure device followed by selective arterial angiography to assess for hemostasis [21,22].

\subsection{Post procedural management/discharge}

After the TAVI procedure, patients are monitored for at least 2-4 h at the Cardiac Care Unit. When the patient is considered to be hemodynamic stable and in the absence of complications, the patient is then transferred to the Medium Care Unit for further observation and mobilization until hospital discharge. Furthermore access site assessment for potential late bleeding and also telemetric monitoring supplemented with regular ECG's for potential conduction abnormalities up to $72 \mathrm{~h}$ post intervention is mandatory. Moreover in terms of early recognition of delirium the geriatrician will evaluate daily the patient (Table $1 \mathrm{~b})$.

The expected discharge is between 3 and 7 days post procedure. Post-TAVI anti-thrombotic therapy consists of Aspirin (lifelong) and Thienopyridine (for three months). In patients indicated for oral anticoagulant therapy, Clopidogrel for three months will be administered.

In addition to a one-month follow-up visit, further follow-up is scheduled at one, three and five year's post-TAVI (Table 1b). In the context of evaluating changes for the degree of AS related symptoms and functional status, patients are asked to complete a generic health status questionnaire (i.e. EuroQOL five dimensions (EQ-5D)) including the visual analogue scale (EQ-VAS) at baseline, twelve months, three and five years [23].

\subsection{Patient safety and quality of care}

The weekly TAVI meeting is attended by the TAVI interventionalist, accompanied by a team of dedicated interventional cardiology fellows involved in the TAVI program and the TAVI nurse coordinator. During this meeting in-hospital post-TAVI patients are discussed and reviewed for post-procedure in-hospital care, eventual complications, length of stay and discharge preparation. Furthermore patients undergoing a planned TAVI procedure in the following week are again assessed according to an adjusted format (i.e. medical history, comorbidities, established risk scores, status of the conduction-system, echooutcomes, status of the coronary anatomy, use of embolic protection, access, closure and possible inclusion in a study).

\section{Data management}

All demographic, clinical complications and related data such as laboratory assays, ECG and echocardiographic data will be collected during the outpatient visits at both the cardiac and geriatric departments. In addition a concise set of variables collected during TAVI are entered into a dedicated database.

Captured data is entered on a structural basis and a collaborative manner in the dedicated TAVI database by three groups of participants; a medical student team accompanying the TAVI-cardiologists during 


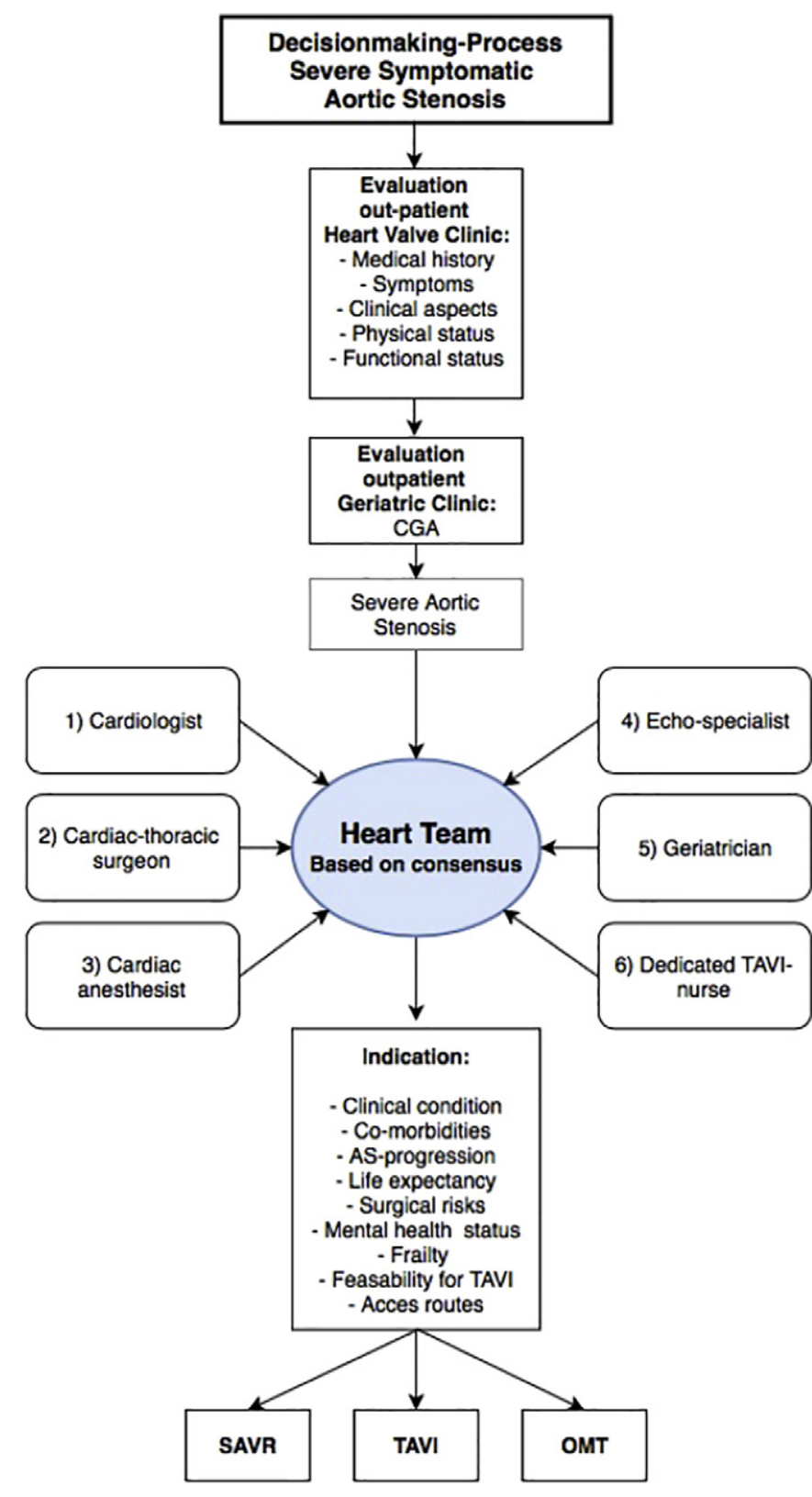

Fig. 1. The heart team multidisciplinary decision-making process.

the outpatient clinic, the fellows involved in the TAVI program and by the geriatrician team members.

The dedicated database is hosted on an internal server. It is not accessible from an external point of contact and it features real time user tracking / logging and facilitates simultaneous /multiple user interaction.

\subsection{TAVI nurse coordinator}

The success of a multi-disciplinary team approach with special attention to patient care is dependent on the organizational skills of a central individual (Fig. 2). The TAVI-nurse coordinator informs at the preadmission phase the patient and his/her relatives regarding the details of the procedure. Also the TAVI nurse oversees the patient's inhospital, discharge and follow-up phases. Knowledge of the patient's pathway, therapy treatment, discharge management and social support is a key factor in the TAVI Care \& Cure program. In addition offering a point of contact to the patient, both in-hospital and post discharge, enhances the patients well-being, benefiting a thorough preparation for, and information about the patient's treatment.

\section{Discussion}

Aortic stenosis is the most common valve disease in elderly adults with a growing prevalence due to the aging population [3]. TAVI, currently performed in over 70 countries [24], has evolved as a less invasive, safe and effective alternative treatment of patients with severe symptomatic AS who are at high or prohibitive risk for surgical aortic valve replacement [2].

Evidence from randomized clinical trials comparing outcomes of SAVR versus TAVI has led to a broadening of indications for TAVI with an expansion from the initial high-risk surgical group onto currently an intermediate and low risk population $[1,25,26]$ resulting in a exponentially volume growth of TAVI worldwide. A shared and balanced decision making strategy by the Heart Valve Team includes an individualized approach of patient specific risk assessment and the use of additional outcome measures reflecting patient related safety and clinical endpoints (i.e. 30-day mortality, VARC-2 variables) [10,12].

Since the first TAVI was performed in 2002 [27], there has been a major evolution of developments and transformation of CE-marked TAVI systems. Furthermore technical advancements in the current device technology have led to amongst others i.e. lower profiles of the delivery systems, retrievable and repositionable features as also improvements in designs leading to a reduction in paravalvular leakage. The most preferred access route is the trans femoral (TF) route. Alternatives are the trans-apical, trans-subclavian and direct aortic route. In addition, the operator experience has intuitively increased, reflecting in a more specified case selection and procedural strategy leading to improved reduction of peri-procedural events and clinical outcomes post TAVI. The Dutch Guidelines for Competencies for Transcatheter Heart Valve Intervention stated that an institution must achieve at least 75 TAVI-procedures per year to be considered "established" within three years of inception of the program [28].

The afore mentioned developments have led to the establishment of this TAVI Care \& Cure program in our center, initiated to collect data from all TAVI patients. Further formalizing and structuring this TAVI program by utilizing the captured data, enables real-time monitoring and improvement of the quality of care, to present transparent reports of site performance on a regular basis providing additional information on i.e. in-hospital and 30-day mortality, vascular complications, bleeding, conductions disturbances and disabling stroke, as well as frailty as predictor for mortality (30-day and 1 year) and HRQoL post TAVI. The advantages of the implementation of TAVI Care \& Cure is the uniformity of data collection, data integrity and analysis, all stored in one dedicated database.

A comprehensive tailored TAVI dataset is now mandatorily, annually reported to the national health inspector via a national registry platform, the Dutch Heart Registry (NHR, Nederlandse Hartregistratie). The NHR is a major cardiovascular quality-of-care registry and aims to monitor and improve quality of care of heart disease for the individual patient by collecting and analyzing patient data, reporting relevant outcome indicators in annually public accessible reports. Additionally an independent academic Clinical Events Committee (CEC) will evaluate regularly adverse events according to international guidelines and definitions (VARC-2, Bleeding Academic Research Consortium (BARC), the ESC Myocardial Infarction Definitions) [29-31].

In terms of specific research questions, two distinct areas will be explored in detail. Firstly as there is a growing interest in the assessment of frailty, which is associated with increased morbidity and mortality after SAVR and TAVI [8]. Frailty has been added in complement to the conventional risk scores (Society of Thoracic Surgeons (STS) score and European System for Cardiac Operative Risk Evaluation (EuroSCOREII)) in the TAVI Care \& Cure program. To incorporate frailty in terms of functionality, HRQoL and other existing disabilities in the patient 

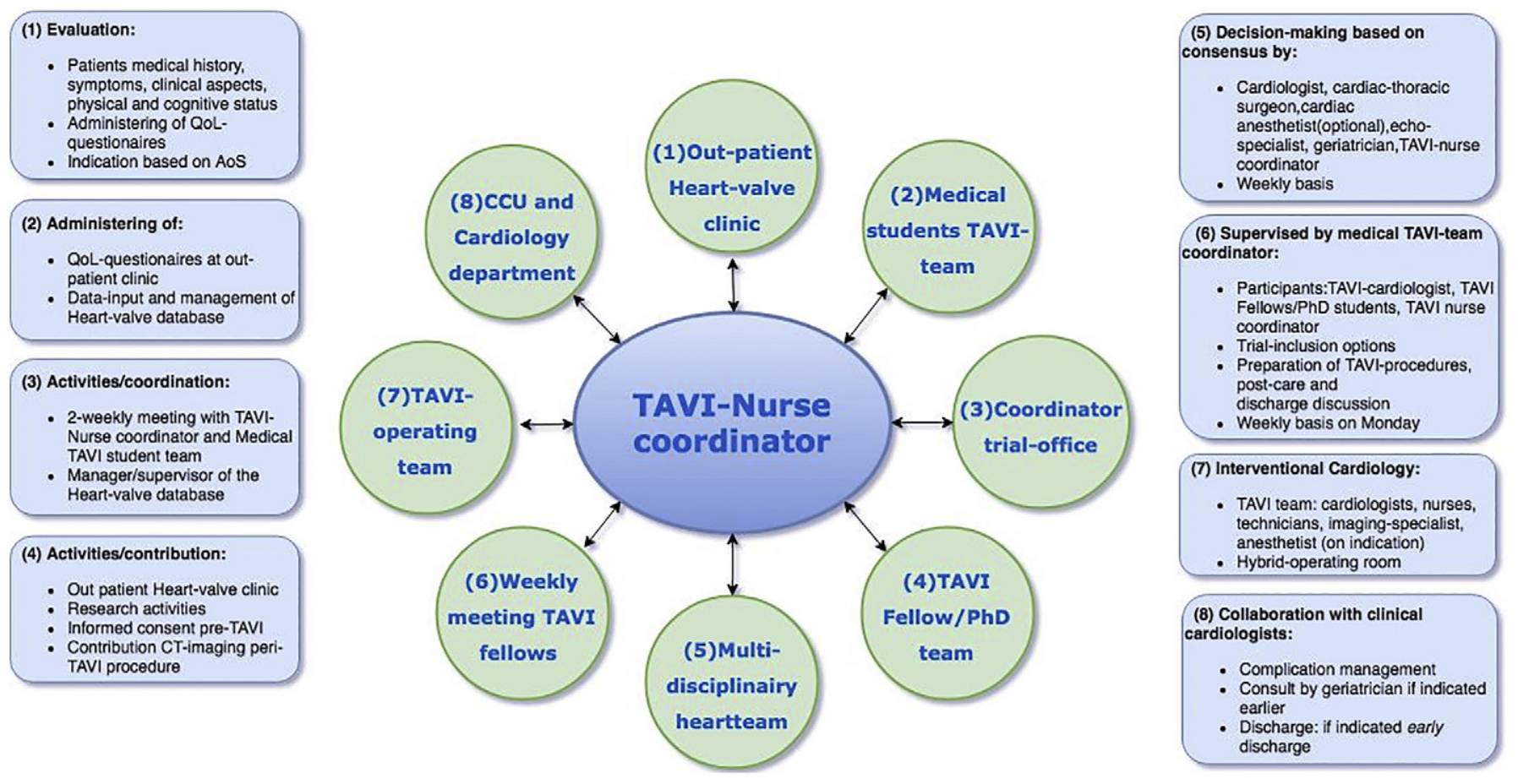

Fig. 2. Contributors in the TAVI-pathway.

selection process, we aim to predict more distinctly the differentiation between those patients who will benefit from TAVI and those who will not. Currently there is debate ongoing concerning the need to develop a dedicated TAVI orientated quality of life questionnaire. The TAVI Care \& Cure data may also contribute to this debate.

Secondly improvements in risk-stratification and patient selection in conjunction with a shift to lower-risk patients coupled with the standardization of TAVI-procedures have led to an early discharge program in our institution. This program simplifies the TAVI-procedure, decreases its duration and reduces procedural related complications by including a fully percutaneous trans femoral access site entry and closure, performed under local anesthesia and early mobilization [32,33].

There is currently no consensus over the definition 'early discharge'. A recent meta-analysis of 8 observational studies including 1775 patients, evaluating early discharge to 30-day mortality, suggests that early discharge by day 3 after TAVI in selected patients who underwent an uncomplicated TAVI is safe in terms of mortality, discharge to 30-day or need for a permanent pacemaker after discharge [34]. Incorporating a simplistic/minimalistic approach into clinical practice starts with performing a pre-procedure screening of patient's functional and cognitive status and suitability for an early discharge pathway. That includes a more refined selection of suitable valve type based upon integrating the pre-procedural ECG interpretations including P-R interval, QRS duration and the electrical axis. It's important to inform the patient and his/her social network that an early discharge can be anticipated if the post-procedural period is uneventful to ensure that one patient's social support and network is prepared for a potential early discharge.

In essence, the ambition of this dedicated TAVI Care \& Cure program is to gain more insights into existing and novel variables.

\section{Conclusion}

With a single center observational registry, we aim to assess the TAVI patient clinical pathway, focusing on pre, peri and post interventional variables including functional status and HRQoL. We will evaluate the patient's complexity by applying an extended multidisciplinary approach, which includes a systematic application of geriatric assessments of frailty and cognitive function.

\section{Authors contributions}

M. De Ronde-Tillmans, J. Goudzwaard, N. El Faquir, N. van Mieghem, F. Mattace-Raso, M. Lenzen, and P. de Jaegere contributed to the design and implementation of the research. M. De Ronde-Tillmans, P. Cummins and J. Goudzwaard were responsible for drafting the article or revising it critically for important intellectual content. All authors approved this version of the manuscript to be published.

\section{Conflict of interest}

The authors report no relationships that could be construed as a conflict of interest.

\section{References}

[1] C.R. Smith, M.B. Leon, M.J. Mack, D.C. Miller, J.W. Moses, L.G. Svensson, E.M. Tuzcu, J.G. Webb, G.P. Fontana, R.R. Makkar, M. Williams, T. Dewey, S. Kapadia, V. Babaliaros, V.H. Thourani, P. Corso, A.D. Pichard, J.E. Bavaria, H.C. Herrmann, J.J. Akin, W.N. Anderson, D. Wang, S.J. Pocock, P.T. Investigators, Transcatheter versus surgical aortic-valve replacement in high-risk patients, N. Engl. J. Med. 364 (23) (2011) 2187-2198.

[2] M.B. Leon, C.R. Smith, M. Mack, D.C. Miller, J.W. Moses, L.G. Svensson, E.M. Tuzcu, J.G. Webb, G.P. Fontana, R.R. Makkar, D.L. Brown, P.C. Block, R.A. Guyton, A.D. Pichard, J.E. Bavaria, H.C. Herrmann, P.S. Douglas, J.L. Petersen, J.J. Akin, W.N. Anderson, D. Wang, S. Pocock, Transcatheter aortic-valve implantation for aortic stenosis in patients who cannot undergo surgery, N. Engl. J. Med. 363 (17) (2010) 1597-1607.

[3] R.L. Osnabrugge, D. Mylotte, S.J. Head, N.M. Van Mieghem, V.T. Nkomo, C.M. LeReun, A.J. Bogers, N. Piazza, A.P. Kappetein, Aortic stenosis in the elderly: disease prevalence and number of candidates for transcatheter aortic valve replacement: a meta-analysis and modeling study, J. Am. Coll. Cardiol. 62 (11) (2013) 1002-1012.

[4] A. Clegg, J. Young, S. Iliffe, M.O. Rikkert, K. Rockwood, Frailty in elderly people, Lancet 381 (9868) (2013) 752-762.

[5] M.R. Reynolds, E.A. Magnuson, Y. Lei, M.B. Leon, C.R. Smith, L.G. Svensson, J.G. Webb, V.C. Babaliaros, B.S. Bowers, W.F. Fearon, H.C. Herrmann, S. Kapadia, S.K. Kodali, R.R. Makkar, A.D. Pichard, D.J. Cohen, Health-related quality of life after transcatheter aortic valve replacement in inoperable patients with severe aortic stenosis, Circulation 124 (18) (2011) 1964-1972.

[6] B.R. Lindman, K.P. Alexander, P.T. O'Gara, J. Afilalo, Futility, benefit, and transcatheter aortic valve replacement, JACC Cardiovasc Interv 7 (7) (2014) 707-716.

[7] J. Afilalo, S. Karunananthan, M.J. Eisenberg, K.P. Alexander, H. Bergman, Role of frailty in patients with cardiovascular disease, Am J Card 103 (11) (2009) 1616-1621.

[8] S. Stortecky, A.W. Schoenenberger, A. Moser, B. Kalesan, P. Jüni, T. Carrel, S. Bischoff, C.-M. Schoenenberger, A.E. Stuck, S. Windecker, Evaluation of multidimensional 
geriatric assessment as a predictor of mortality and cardiovascular events after transcatheter aortic valve implantation, JACC Cardiovasc Interv 5 (5) (2012) 489-496.

[9] A.W. Schoenenberger, S. Stortecky, S. Neumann, A. Moser, P. Jüni, T. Carrel, C. Huber, M. Gandon, S. Bischoff, C.M. Schoenenberger, A.E. Stuck, S. Windecker, P. Wenaweser, Predictors of functional decline in elderly patients undergoing transcatheter aortic valve implantation (TAVI). Eur Heart J. 34 (9) (2013) 684-692.

[10] Baumgartner H, Falk V, Bax JJ, De Bonis M, Hamm C, Holm PJ, Iung B, Lancellotti P, Lansac E, Rodriguez Munoz D, Rosenhek R, Sjogren J, Tornos Mas P, Vahanian A, Walther T, Wendler O, Windecker S, Zamorano JL, Group ESCSD. 2017 ESC/EACTS guidelines for the management of valvular heart disease. Eur. Heart J. 2017;38 (36):2739-2791.

[11] L.P. Fried, C.M. Tangen, J. Walston, A.B. Newman, C. Hirsch, J. Gottdiener, T. Seeman, R. Tracy, W.J. Kop, G. Burke, Frailty in older adults evidence for a phenotype, J. Gerontol. Ser. A Biol. Med. Sci. 56 (3) (2001) M146-M157.

[12] A.P. Kappetein, S.J. Head, P. Genereux, N. Piazza, N.M. van Mieghem, E.H. Blackstone, T.G. Brott, D.J. Cohen, D.E. Cutlip, G.A. van Es, R.T. Hahn, A.J. Kirtane, M.W. Krucoff, S Kodali, M.J. Mack, R. Mehran, J. Rodes-Cabau, P. Vranckx, J.G. Webb, S. Windecker, P.W. Serruys, M.B. Leon, Valve Academic Research Consortium, Updated standardized endpoint definitions for transcatheter aortic valve implantation: the Valve Academic Research Consortium-2 consensus document, Eurolntervention 8 (7) (2012) 782-795.

[13] M.F. Folstein, S.E. Folstein, P.R. McHugh, "Mini-mental state": a practical method for grading the cognitive state of patients for the clinician, J. Psychiatr. Res. 12 (3) (1975) 189-198

[14] P. Abizanda, J.L. Navarro, M.I. Garcia-Tomas, E. Lopez-Jimenez, E. Martinez-Sanchez G. Paterna, Validity and usefulness of hand-held dynamometry for measuring muscle strength in community-dwelling older persons, Arch. Gerontol. Geriatr. 54 (1) (2012) 21-27.

[15] S.F.A. Katz, R.W. Moskowitz, B.A. Jackson, M.W. Jaffe, Studies of illness in the aged. The index of Adl: a standardized measure of biological and psychosocial function, JAMA 185 (1963) 914-919.

[16] M.P.B.E. Lawton, Assessment of older people: self-maintaining and instrumental activities of daily living, Gerontologist 9 (3) (1969) 179-186.

[17] T.M.H.T. Steffen, L. Mollinger, Age- and gender-related test performance in community-dwelling elderly people: six-minute walk test, Berg balance scale, timed up \&amp; go test, and gait speeds, Phys Ther 82 (2) (2002) 128-137.

[18] D. Podsiadlo, S. Richardson, The timed "Up \& Go": a test of basic functional mobility for frail elderly persons, J. Am. Geriatr. Soc. 39 (2) (1991) 142-148.

[19] N.M. Van Mieghem, L. van Gils, H. Ahmad, F. van Kesteren, H.W. van der Werf, C. Brueren, M. Storm, M. Lenzen, J. Daemen, A.F. van den Heuvel, P. Tonino, J. Baan, P.J. Koudstaal, M.E. Schipper, A. van der Lugt, P.P. de Jaegere, Filter-based cerebral embolic protection with transcatheter aortic valve implantation: the randomised MISTRAL-C trial, EuroIntervention 12 (4) (2016) 499-507.

[20] L. Van Gils, H. Kroon, J. Daemen, C. Ren, A.M. Maugenest, M. Schipper, P.P. De Jaegere, N.M. Van Mieghem, L. Van Gils, H. Kroon, J. Daemen, C. Ren, A.M. Maugenest, M. Schipper, P.P. De Jaegere, N.M. Van Mieghem, Complete filterbased cerebral embolic protection with transcatheter aortic valve replacement, Catheter. Cardiovasc. Interv. 91 (4) (2018) 790-797.

[21] A. Chieffo, G.L. Buchanan, N.M. Van Mieghem, D. Tchetche, N. Dumonteil, A. Latib, R.M. van der Boon, O. Vahdat, B. Marcheix, B. Farah, P.W. Serruys, J. Fajadet, D. Carrie, P.P. de Jaegere, A. Colombo, Transcatheter aortic valve implantation with the Edwards SAPIEN versus the Medtronic CoreValve Revalving system devices: a multicenter collaborative study: the PRAGMATIC Plus Initiative (Pooled-RotterdAm-Milano-Toulouse In Collaboration), J. Am. Coll. Cardiol. 61 (8) (2013) 830-836.

[22] N.M. Van Mieghem, A. Latib, J. van der Heyden, L. van Gils, J. Daemen, T. Sorzano, J. Ligthart, K. Witberg, T. de Kroon, N. Maor, A. Mangieri, M. Montorfano, P.P. de Jaegere, A. Colombo, G. Roubin, Percutaneous plug-based arteriotomy closure device for large-bore access: a multicenter prospective study, JACC Cardiovasc Interv 10 (6) (2017) 613-619.
[23] A.J.B. Szende, J. Cabases, Self-reported Population Health: An International Perspective based on EQ-5D, Springer, Dordrecht Heidelberg New York London, 2016 3108-2016.

[24] T.P. Vahl, S.K. Kodali, M.B. Leon, Transcatheter aortic valve replacement 2016: a modern-day "through the looking-glass" adventure, J. Am. Coll. Cardiol. 67 (12) (2016) 1472-1487.

[25] M.B. Leon, C.R. Smith, M.J. Mack, R.R. Makkar, L.G. Svensson, S.K. Kodali, V.H. Thourani, E.M. Tuzcu, D.C. Miller, H.C. Herrmann, D. Doshi, D.J. Cohen, A.D. Pichard, S. Kapadia, T. Dewey, V. Babaliaros, W.Y. Szeto, M.R. Williams, D. Kereiakes, A. Zajarias, K.L. Greason, B.K. Whisenant, R.W. Hodson, J.W. Moses, A. Trento, D.L. Brown, W.F. Fearon, P. Pibarot, R.T. Hahn, W.A. Jaber, W.N. Anderson, M.C. Alu, J.G. Webb, P. Investigators, Transcatheter or surgical aortic-valve replacement in intermediate-risk patients, N. Engl. J. Med. 374 (17) (2016) 1609-1620.

[26] M.J. Reardon, N.M. Van Mieghem, J.J. Popma, N.S. Kleiman, L. Sondergaard, M. Mumtaz, D.H. Adams, G.M. Deeb, B. Maini, H. Gada, S. Chetcuti, T. Gleason, J. Heiser, R. Lange, W. Merhi, J.K. Oh, P.S. Olsen, N. Piazza, M. Williams, S. Windecker, S.J. Yakubov, E. Grube, R. Makkar, J.S. Lee, J. Conte, E. Vang, H. Nguyen, Y. Chang, A.S. Mugglin, P.W. Serruys, A.P. Kappetein, S. Investigators, Surgical or transcatheter aortic-valve replacement in intermediate-risk patients, N. Engl. J. Med. 376 (14) (2017) 1321-1331.

[27] A. Cribier, H. Eltchaninoff, A. Bash, N. Borenstein, C. Tron, F. Bauer, G. Derumeaux, F. Anselme, F. Laborde, M.B. Leon, Percutaneous transcatheter implantation of an aortic valve prosthesis for calcific aortic stenosis: first human case description, Circulation 106 (24) (2002) 3006-3008.

[28] NVT and NVVC Working Group THI, Dutch Guidelines for Competencies for Transcatheter Heart Valve Intervention, 2017.

[29] A.P. Kappetein, S.J. Head, P. Genereux, N. Piazza, N.M. van Mieghem, E.H. Blackstone, T.G. Brott, D.J. Cohen, D.E. Cutlip, G.A. van Es, R.T. Hahn, A.J. Kirtane, M.W. Krucoff, S. Kodali, M.J. Mack, R. Mehran, J. Rodes-Cabau, P. Vranckx, J.G. Webb, S. Windecker, P.W. Serruys, M.B. Leon, Valve Academic Research C, Updated standardized endpoint definitions for transcatheter aortic valve implantation: the Valve Academic Research Consortium-2 consensus document, J. Thorac. Cardiovasc. Surg. 145 (1) (2013) 6-23.

[30] R. Mehran, S.V. Rao, D.L. Bhatt, C.M. Gibson, A. Caixeta, J. Eikelboom, S. Kaul, S.D. Wiviott, V. Menon, E. Nikolsky, V. Serebruany, M. Valgimigli, P. Vranckx, D. Taggart, J.F. Sabik, D.E. Cutlip, M.W. Krucoff, E.M. Ohman, P.G. Steg, H. White, Standardized bleeding definitions for cardiovascular clinical trials: a consensus report from the Bleeding Academic Research Consortium, Circulation 123 (23) (2011) 2736-2747.

[31] K. Thygesen, J.S. Alpert, A.S. Jaffe, B.R. Chaitman, J.J. Bax, D.A. Morrow, H.D. White, Executive Group on behalf of the Joint European Society of Cardiology/American College of Cardiology/American Heart Association/World Heart Federation Task Force for the Universal Definition of Myocardial I. Fourth universal definition of myocardial infarction (2018), Circulation 138 (20) (2018) e618-e651.

[32] M.C. Hyman, S. Vemulapalli, W.Y. Szeto, A. Stebbins, P.A. Patel, R.A. Matsouaka, H.C. Herrmann, S. Anwaruddin, T. Kobayashi, N.D. Desai, P. Vallabhajosyula, F.H. McCarthy, R. Li, J.E. Bavaria, J. Giri, Conscious sedation versus general anesthesia for transcatheter aortic valve replacement: insights from the National Cardiovascular Data Registry Society of Thoracic Surgeons/American College of Cardiology Transcatheter Valve Therapy Registry, Circulation 136 (22) (2017) 2132-2140.

[33] N.P. Mayr, J. Michel, S. Bleiziffer, P. Tassani, K. Martin, Sedation or general anesthesia for transcatheter aortic valve implantation (TAVI), J Thorac Dis 7 (9) (2015) 1518-1526.

[34] R.A. Kotronias, M. Teitelbaum, J.G. Webb, D. Mylotte, M. Barbanti, D.A. Wood, B. Ballantyne, A. Osborne, K. Solo, C.S. Kwok, M.A. Mamas, R. Bagur, Early versus standard discharge after transcatheter aortic valve replacement: a systematic review and meta-analysis, JACC Cardiovasc Interv 11 (17) (2018) 1759-1771. 